\title{
Supplementary Material \\ Satellite Mapping of PM2.5 Episodes in the Wintertime San Joaquin Valley: A "Static" Model Using Column Water Vapor
}

\author{
Robert B Chatfield ${ }^{1}$, Meytar Sorek-Hamer ${ }^{1,2}$, Robert F Esswein ${ }^{1,3}$, and ${ }^{4}$ Alexei Lyapustin ${ }^{4}$ \\ ${ }^{1}$ NASA Ames Research Center, Moffett Field, CA 94035, USA \\ ${ }^{2}$ Universities Space Research Association, Moffett Field, CA, USA \\ ${ }^{3}$ Bay Area Environmental Institute, Moffett Field, CA, USA \\ ${ }^{4}$ NASA Goddard Space Flight Center, MD, USA \\ Correspondence to: Robert B. Chatfield (Robert.B.Chatfield@nasa.gov)
}

\begin{abstract}
Included below are three portions of a poster presented by Michael Shook at the American Geophysical Union (Shook et al., 2013) soon after the DISCOVER-AQ measurements in California. That work gave a syncretic overview of many trace species measurement besides water vapor which motivated our investigation, as described in Section 1.1.. First, there is an acknowledgement of the many authors contributing measurements. Second, there is an explanation of methods of estimating a characteristic mixed layer height as observed of airplane measurements. Third, there are graphs of vertical profiles normalized by average tracer concentration and also by the depth of the mixed layer. The commonalities and some differences of the first tracer shown (water vapor) and the last (particulate scattering).
\end{abstract}

\footnotetext{
A43A-0228: Daily Evolution of Boundary Layer Properties based on NASA DISCOVER-AQ Airborne Profiles over the California San Joaquin Valley. 


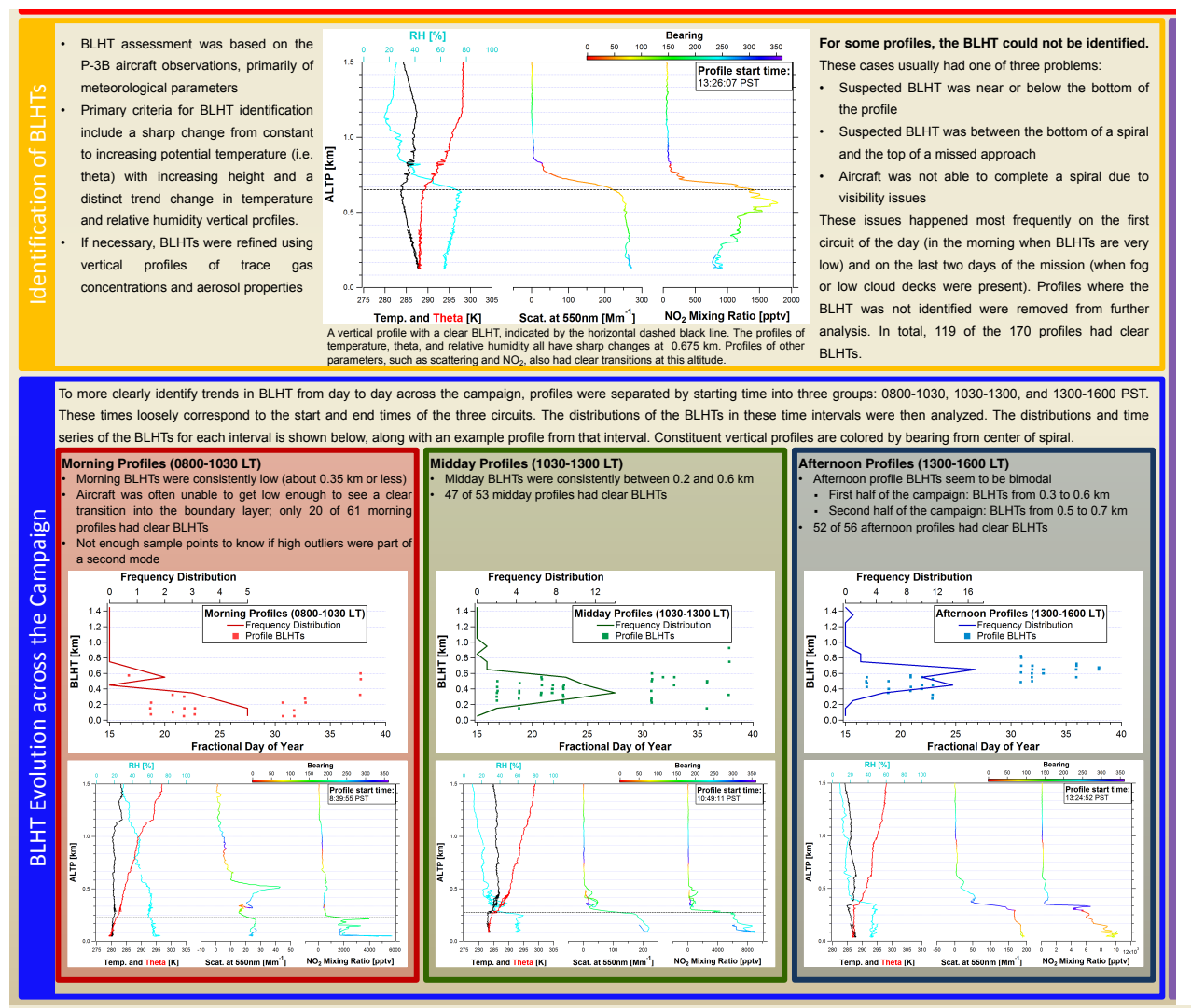

To visualize BL variability and vertical gradients, composite profiles for eight different constituents were created. Constituents were chosen to represent a variety of lifetimes and production/removal processes.

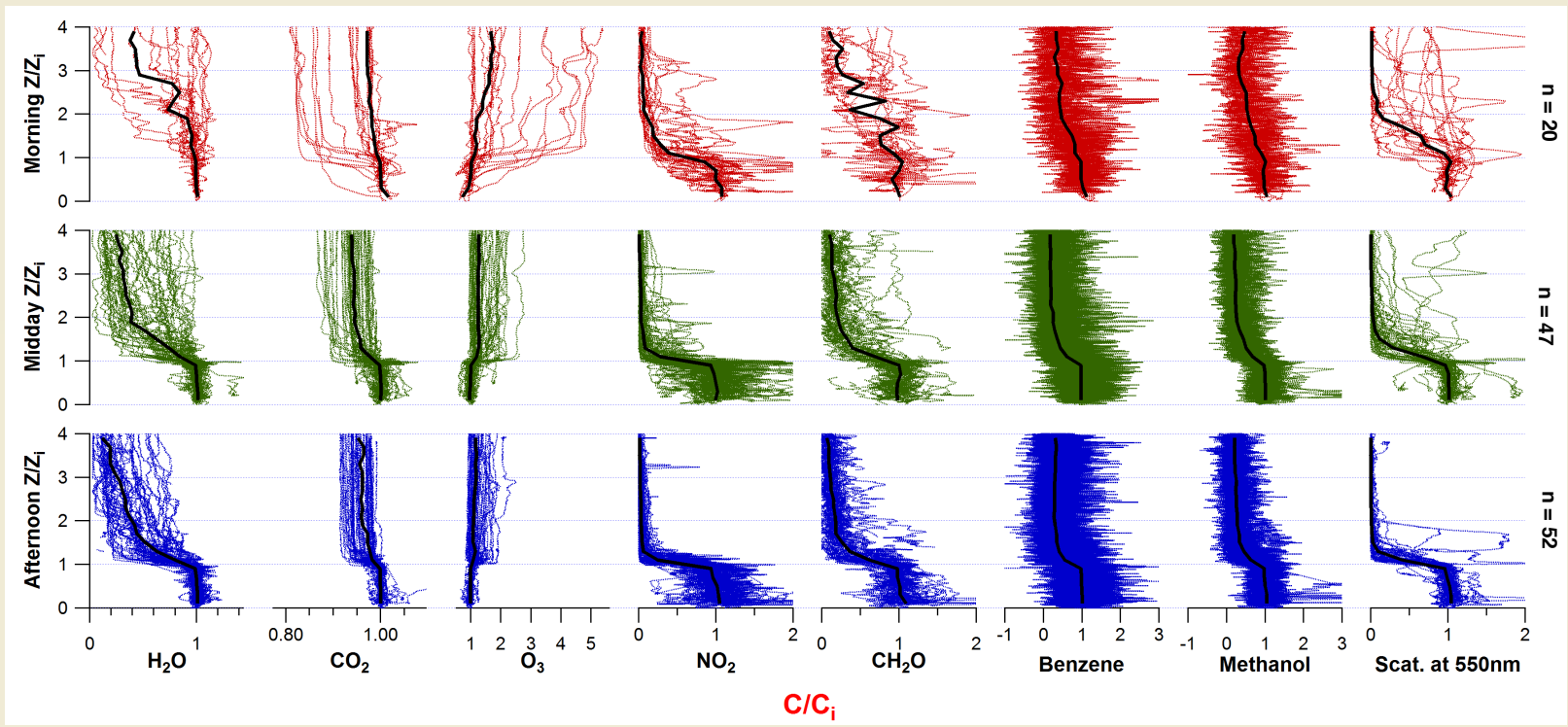

Composite profiles of different constituents scaled by the profile BLHT and the average concentration of the constituent within the boundary layer. The dotted, colored lines represent individual profiles, and the solid black lines represent the median profile for that constituent and time period.

$\mathrm{Z}=$ pressure altitude, $\mathrm{Z}_{\mathrm{i}}=$ profile $\mathrm{BLHT}, \mathrm{C}=$ constituent concentration, and $\mathrm{C}_{\mathrm{i}}=$ average constituent concentration in the boundary layer 